\title{
Virtual outpatient clinic as an alternative to an actual clinic visit after surgical discharge: a randomised controlled trial
}

\author{
Paul Healy, ${ }^{1}$ Liam McCrone, ${ }^{2}$ Roisin Tully, ${ }^{2}$ Emer Flannery, ${ }^{2}$ Aoife Flynn, ${ }^{2}$ \\ Caitriona Cahir, ${ }^{3}$ Mayilone Arumugasamy, ${ }^{1}$ Thomas Walsh ${ }^{1}$
}

\begin{abstract}
1 Department of Surgery, Connolly Hospital, Royal College of Surgeons in Ireland, Dublin, Ireland

${ }^{2}$ Department of General Surgery, Connolly Hospital, Dublin, Ireland

${ }^{3}$ Division of Population Health Sciences, Royal College of Surgeons in Ireland, Dublin, Ireland
\end{abstract}

\section{Correspondence to} Dr Paul Healy, Department of Surgery, Connolly Hospital, Royal College Of Surgeons in Ireland, Dublin 15, Ireland; drpaulhealy@gmail.com

Received 4 April 2018 Revised 6 July 2018 Accepted 7 August 2018 Published Online First 5 October 2018

\section{Sinked}

- http://dx.doi.org/10.1136/ bmjqs-2018-008697

\section{Check for updates}

(C) Author(s) (or their employer(s)) 2019. No commercial re-use. See rights and permissions. Published by BMJ.

To cite: Healy P, McCrone L, Tully R, et al. BMJ Qual Saf 2019;28:24-31.

\begin{abstract}
Background It is standard practice to review all patients following discharge at a follow-up clinic but demands on all health services outweigh resources and unnecessary review appointments may delay or deny access to patients with greater needs.

Aims This randomised trial aimed to establish whether a virtual outpatient clinic (VOPC) was an acceptable alternative to an actual outpatient clinic (OPC) attendance for a broad range of general surgical patients following a hospital admission.

Patients and methods All patients admitted under one general surgical service over the study period were assessed. If eligible for inclusion the rationale, randomisation and follow-up methods were explained, consent was sought and patients randomised to receive either a VOPC or an OPC appointment.

Results Two-hundred and nine patients consented to study inclusion, of which $98 / 107(91.6 \%)$ in the VOPC group and 83/102 (81.4\%) in the OPC group were successfully contacted. Only 6 patients in the OPC group and 10 in the VOPC group reported ongoing issues. A further follow-up indicated 78 of 82 (95\%) VOPC patients were very happy with their overall experience compared with $34 / 61$ (56\%) in the actual OPC group $(\mathrm{p}<0.001)$. A significant proportion of both cohorts-68/82 (83\%) in VOPC group and 41/61 $(67 \%)$ in OPC group $(p=0.029)$ - preferred a VOPC appointment as their future follow-up of choice.

Conclusions The majority of patients discharged from a surgical service could be better followed up by a virtual clinic with a significant proportion of patients reporting a preference for and a greater satisfaction with such a service.
\end{abstract}

\section{INTRODUCTION}

The surgical outpatient clinic (OPC) is the first point of contact between most patients and the surgical team, where they are assessed, investigations ordered and treatment plans devised. Following surgery or non-surgical treatment, it has been standard practice to review all patients at a follow-up clinic visit ${ }^{1-3}$ but the value of this practice has been questioned for a variety of reasons. The waiting time to access such a service is a commonly measured key performance indicator (KPI), with defined target waiting times in different national healthcare settings. ${ }^{45}$ Current clinical demands outweigh available resources and these targets are often missed. Unnecessary review appointments for patients who are well have the potential to increase adverse healthcare outcomes by delaying access for assessment and diagnosis of patients with more serious conditions. ${ }^{67}$ Routine OPC follow-up is also a burden on patients and relatives, who may miss work or college, have to travel long distances and wait for prolonged periods to be seen. There is also an associated financial burden of absence from work and other costs relating to transport costs and hospital parking charges.

Previous studies have demonstrated that telephone follow-up is a safe and acceptable alternative to traditional outpatient appointments in both the adult and paediatric settings, following anorectal surgery, cholecystectomy, hernia repair, tonsillectomy and cataract surgery. ${ }^{28-13}$ Improved efficiency and high levels of patient satisfaction have also been demonstrated with a virtual OPC following endoscopy. ${ }^{14} \mathrm{~A}$ systematic review comparing telephone consultations to face-to-face outpatient consultations after surgery, however, concluded that relevant studies to date were overall of poor methodological quality and were unable to draw definite conclusions. ${ }^{15}$

The aim of this randomised trial was to establish whether a virtual outpatient clinic (VOPC) was a safe and acceptable alternative to clinic attendance for 
Table 1 Inclusion and exclusion criteria

\begin{tabular}{ll}
\hline Inclusion criteria & Exclusion criteria \\
\hline $\begin{array}{l}\text { Over } 16 \text { years old } \\
\text { Could provide written consent }\end{array}$ & Declined to participate \\
$\begin{array}{l}\text { Comprised one offour categories based on reason for admission } \\
\text { Category } 1 \text { - minorsurgery }\end{array}$ & $\begin{array}{l}\text { On-going issues requiring follow up such as wound healing problems } \\
\text { Required further investigation such as endoscopy after admission with } \\
\text { Category } 2 \text { - elective or emergency surgery such as appendicectomy, hernia }\end{array}$ \\
$\begin{array}{l}\text { repair, thyroidectomy } \\
\text { Category } 3 \text { - admitted for investigation or management of conditions such as }\end{array}$ \\
$\begin{array}{l}\text { non-specific abdominalpain, head injury, cellulitis } \\
\begin{array}{l}\text { Category } 4 \text { - attended for surveillance endoscopy for conditions such as } \\
\text { colonic polyps or Barrett's oesophagus }\end{array}\end{array}$ \\
\hline
\end{tabular}

a broad range of general surgical patients following a hospital admission.

\section{PATIENTS AND METHODS}

A randomised controlled trial was conducted at a government funded and University affiliated teaching hospital in Dublin, Ireland. The hospital provides a a 24 hour emergency department, acute surgical, medical and psychiatry services, day care, outpatient care, long-stay residential care plus diagnostic and therapeutic support services to a catchment population of 370000 . Healthcare is also provided within the state by private healthcare providers.

The study was conducted between May 2016 and April 2017 and this time period included granting of ethical approval, a recruitment period of 4 months and follow-up. Ethical approval was obtained from the hospital's Research Ethics Committee and the trial was registered at http://www.clinicatrials.gov, registration number NCT03067220.

\section{Patient selection and randomisation}

All patients admitted under the care of one surgical service (two consultants and seven non-consultant staff), either as elective or emergency admissions, over a 4-month period, were assessed for predetermined inclusion and exclusion criteria (table 1). If eligible for inclusion, patients were approached prior to discharge and the study rationale, randomisation method and potential methods of follow-up were explained. If they agreed to participate, an information leaflet about the study was provided and written consent was obtained. Any follow-up required before the OPC or VOPC review such as removal of sutures/staples or changes of dressings was arranged as usual via the local public nurse service or family doctor.

Patients were randomised by members of the medical team who selected a non-transparent envelope, which contained either a coloured card indicating a VOPC follow-up by telephone call within 6-8 weeks or a white card indicating follow-up with an OPC appointment at 6-8 weeks. After randomisation, the patient was provided with a letter detailing their specific follow-up arrangements and a contact number was provided if they had any further questions after discharge. Patients were sent a further letter by administration staff after discharge, with the specific date of either the clinic appointment or phone follow-up.

\section{Data collection}

Data were collected prospectively on all admissions during the study period using a password protected Excel sheet. Information recorded included name, date of birth, chart number, date of admission and discharge, whether an elective or emergency admission, diagnosis, any procedure performed, result of randomisation and reason for exclusion if relevant.

\section{The actual OPC review}

The surgical service delivered consultant led clinics two times per week. Patients attending the clinic were a mix of new referrals and review patients. Either a consultant or non-consultant doctor saw patients in order of arrival. All new patients seen were either discussed with the consultant or seen directly by them, as were all patients with difficult or complex issues. All review patients were seen and assessed by non-consultant doctors and only those reporting ongoing issues were then reviewed by the consultant.

\section{The VOPC review}

The VOPC was conducted by two non-consultant team members (senior house officer and a registrar) who had over 10 years postgraduate experience between them, over three afternoons per week for a period of 2 hours each afternoon. Administration staff retrieved the medical notes from medical records department prior to the clinic which was located in a room with access to direct dial telephones and hospital radiology, laboratory and pathology systems. This was achieved using existing resources and did not require any additional financial or technical support.

On contacting the patient, the reason for the call was explained, any issues since discharge were identified and discussed and the result of pending investigations such as radiology or histology was explained. 
There was no standardised script and each doctor used their own approach to the conversation as they would in an OPC setting. The result of the discussion was documented in the medical chart and a letter dictated to their family doctor. If there were any ongoing issues or concerns or if the patient requested a clinic appointment, this was provided for at the next OPC where a consultant was available to review. For those who did not answer (DNAn) the telephone, there were two further attempts to contact them during the same clinic (one further call to their registered number and one call to their next of kin). If there was no contact, this was documented and a letter sent to their family doctor.

\section{Satisfaction with follow-up assessment}

A second evaluation was performed approximately 2 months after the final clinic review (VOPC or OPC) via telephone questionnaire to evaluate the overall experience of the method of follow-up and preferred method of follow-up in the future. This questionnaire also provided patients a further opportunity to report on any ongoing symptoms or complications of treatment.

\section{Outcomes}

The primary outcome was the reported rate of complications or ongoing issues in either group at follow-up appointment after discharge. Secondary outcomes included a 'did not answer' (DNAn) or 'did not attend' (DNA) rate and the number of patients requiring further procedures or investigation. The final outcome was patient satisfaction with their experience, and the time and cost consequences associated with an OPC visit versus a VOPC clinic and the patients' preference for future follow-up.

\section{Statistical methods}

Data were analysed with Stata Release V.15.1. Differences between groups on categorical variables were tested with the $\chi^{2}$ test and on ordinal variables with the Wilcoxon Mann-Whitney test. Differences in rates are used to calculate numbers needed to treat.

It was intended to use a 5-point scale to assess patient satisfaction with the assigned interventions. It can, however, be difficult to assess sample size requirements for such scales as the distributions are unlikely to be known in advance. However, we examined potential scenarios. Sample size was based on the premise that patients are unlikely to rate themselves as dissatisfied with care, so the majority of patients would use the fourth or fifth points on the scale, with a minority on the central point.

A sample size of just over 100 per group was calculated to give $90 \%$ power to detect a difference between a $10 \%, 60 \%$ and $30 \%$ in the neutral, positive and highly positive categories and a distribution of 30\%, $50 \%$ and $20 \%$ (using the $\mathrm{R}$ package sample size).

\section{RESULTS}

A total of 365 patients were admitted for an elective or emergency episode of care by the service during the recruitment period. Of these, 209 patients were eligible for inclusion. After consent was obtained, 107 were randomised to telephone follow-up from the VOPC and 102 were randomised to OPC attendance (figure 1). Demographic data, type of admission and category of intervention by each randomised group are outlined in table 2 .

\section{VOPC contact or actual OPC attendance}

Of the 107 patients randomised to the VOPC follow-up, $98(91.6 \%)$ were successfully contacted of which 88 (89.7\%) were discharged from follow-up while 10 had issues as outlined below. Nine of 107 patients (8.4\%) were not contactable despite numerous attempts including attempts to contact next of kin. Based on available results, none of these patients required follow-up and this was communicated by mail to the last registered address documented on their previous admission and to their family doctor.

Of 102 patients allocated to the actual OPC, 83 (81.4\%) attended for their appointment, of which 67 $(80.7 \%)$ were successfully discharged to their family doctor while 16 required further attention as outlined below. A total of 7/102 (6.9\%) patients made an effort to contact the clinic and cancel their appointment saying they felt it was unnecessary and a further $12 / 102$ patients $(11.8 \%)$ DNA and did not contact the clinic to cancel.

As randomised, there was no difference between the proportion of patients requiring further attention in the VOPC $(10 / 107,9.3 \%)$ and OPC $(16 / 102,16 \%$, $\mathrm{p}=0.017, \chi^{2}$ test). Although the rate of issues requiring attention among patients who received a VOPC assessment was almost half of that in patients seen in OPC (11\% vs $19 \%)$, this difference was likewise not statistically significant $\left(\mathrm{p}=0.150, \chi^{2}\right.$ test).

The difference in patient contact rates is statistically significant $\left(p=0.030, \chi^{2}\right.$ test). On the basis of successful patient follow-up, the use of VOPC gives a number needed to treat (NNT) of one extra patient follow-up for 9.8 patients assigned to VOPC.

\section{Complications and clinic outcomes}

None of the 98 patients contacted via the VOPC reported complications of their management but six (6.1\%) reported ongoing symptoms and were offered an OPC review the following week as per the study protocol. Of those six, only three attended; one reported a swelling at site of a hernia operation (normal examination), one had concerns about recurrence of a skin lesion (no recurrence) and one had ongoing rectal bleeding (booked for banding of haemorrhoids). Three patients DNA; two had reported intermittent pain and one had a suspected wound infection. The family doctor of these patients was subsequently contacted 


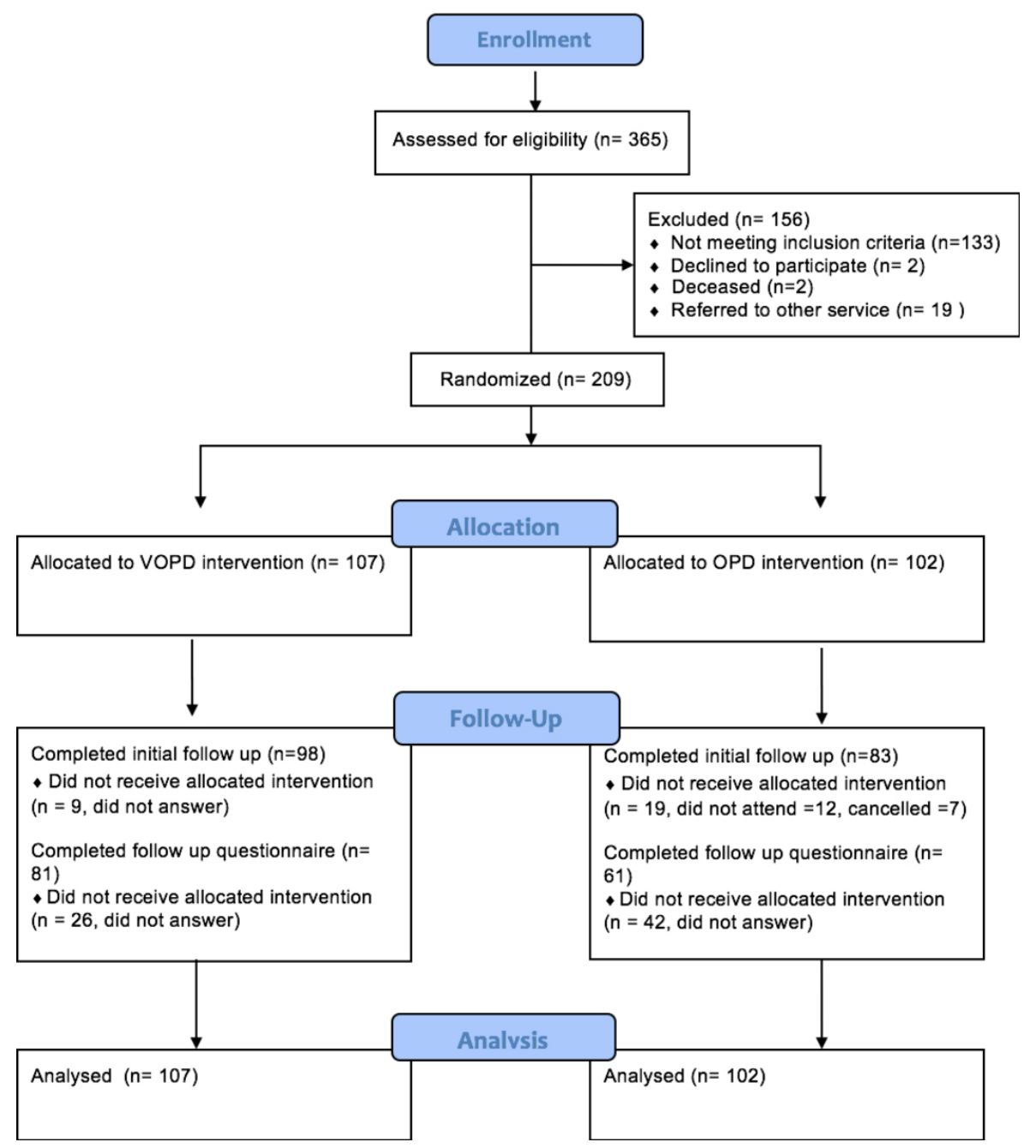

Figure 1 Consort flow diagram.

and confirmed that the two reporting pain they had not attended the practice for review and the third as treated with an antibiotic for a surgical site infection.

A further four (4.1\%) patients were listed directly for further procedures; one for sigmoidoscopy, one for surveillance endoscopy for Barrett's oesophagus and two for surveillance colonoscopies for colonic polyps (figure 2).

Of the 83 patients who attended the actual OPC, 5 (6\%) reported ongoing issues of which 2 were booked for CT/US abdomen for unexplained symptoms, 2 were referred to other specialties and 1 patient was booked for a further review in 3 months. A further 12 patients (14.4\%) were listed for further investigations such as upper or lower gastrointestinal endoscopy. While 8/12 patients were booked for surveillance endoscopy for clearly documented reasons, there was no clear or apparent reason for these investigations being rebooked in $4 / 12$ patients. The difference between cohorts in the number of further investigations/procedures requested, however, was not statically significant.
Patient satisfaction and preference for future followup

The telephone evaluation conducted successfully made contact with 82/107 (76.6\%) patients in the VOPC group and 61/102 (59.8\%) patients in the OPC group. Six patients in the OPC group and 10 patients in the VOPC group reported ongoing, recurrent or intermittent symptoms.

Patients in the VOPC group had higher satisfaction ratings ( $\mathrm{p}<0.001$, Wilcoxon Mann-Whitney test) with $95 \%$ of the VOPC group rating their overall experience as 'very satisfied' against $56 \%$ of the OPC group. No patient in either cohort expressed any dissatisfaction. The VOPC group also had higher satisfactions scores for their interaction with the clinician $(\mathrm{p}<0.001$, Wilcoxon Mann-Whitney test) (figure 2). A majority of both cohorts, 41/61 (67\%) in OPC group and 68/82 (83\%) in VOPC group, reported a VOPC appointment as their preferred method of follow-up in the future ( $p=0.029, \chi^{2}$ test) (figure 3$)$.

Over half of patients contacted in the VOPC arm stated they would have had to miss either a half or full 


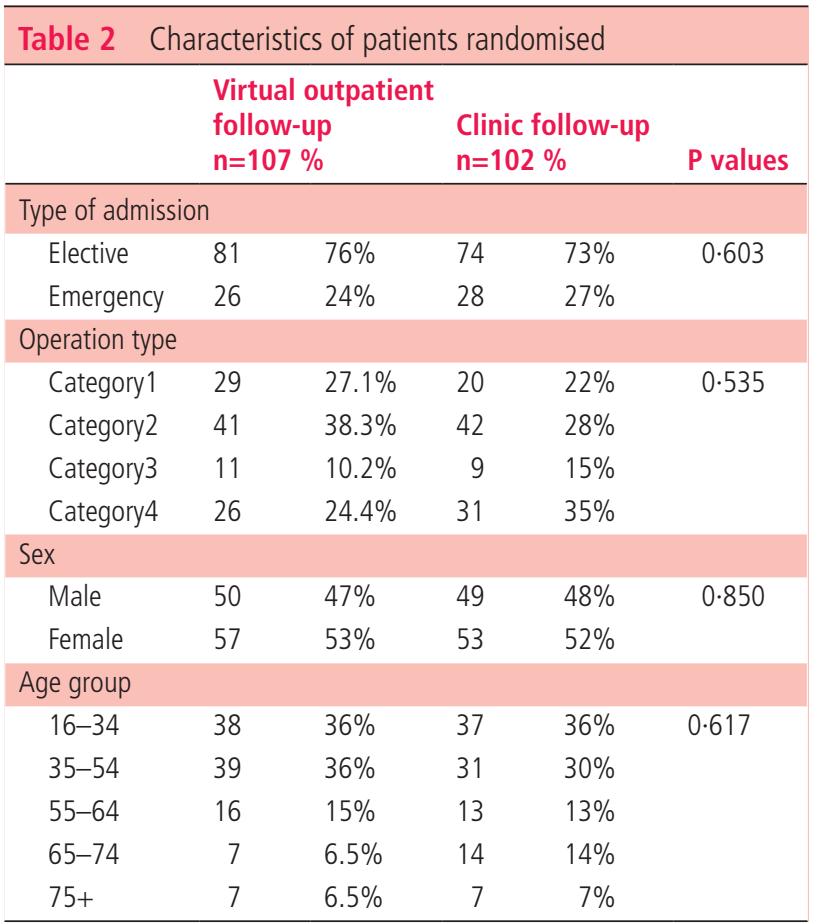

day from work if they had to attend for an OPC rather than being contacted by telephone. Attendees of the OPC also reported a mean waiting time to be seen of 49 min. A summary and comparison of the results of the questionnaire are listed in table 3.

\section{DISCUSSION}

Following discharge from hospital, follow-up practice varies among surgeons. While some do not follow up standard procedures such as hernia repair, cholecystectomy or appendicectomy, ${ }^{8}$ others advocate routine follow-up citing the need to monitor patient progress, patient preference and family doctor concerns of increased workload. ${ }^{16}$ To our knowledge, there has been no definitive evidence to show that a no follow-up policy is safe and acceptable to patients or indeed evidence to suggest that a mandatory follow-up policy is necessary. In order to address the variance in clinical practice among surgeons and to acknowledge patient and family doctor concerns, we conducted a randomised trial that has shown that a VOPC is a safe and acceptable alternative to clinic attendance for a broad range of general surgical patients following a hospital admission.

Over $85 \%$ of all patients reviewed were successfully discharged and there were no issues identified that could not be dealt with by telephone. Of those requiring further investigations or follow-up in the OPC arm, the associated workload was mainly administrative. The cancellation and DNA rate for the real clinic was high, denying a significant number of new patients an assessment opportunity. Of note, a greater proportion of the OPC cohort were also uncontactable for the follow-up questionnaire. It is possible that the difference in follow-up rates is because people who have issues are likely to be compliant with follow-up while people who do not have issues are likely to skip their appointment. Skipping is more likely to happen if you have to attend OPD in person. An important point is that those who do not attend because they are asymptomatic may nevertheless have issues that are undetected unless they are interviewed, so the increased contact rate with VOPD is a potential benefit.

The attendees of the real clinic generated more investigations including imaging or endoscopy compared with the VOPC which is difficult to explain. Perhaps, having attended for follow-up, paid for parking and waited for significant durations, patients required satisfaction and junior doctors found it easier to investigate further than to reassure. Those patients reporting any ongoing

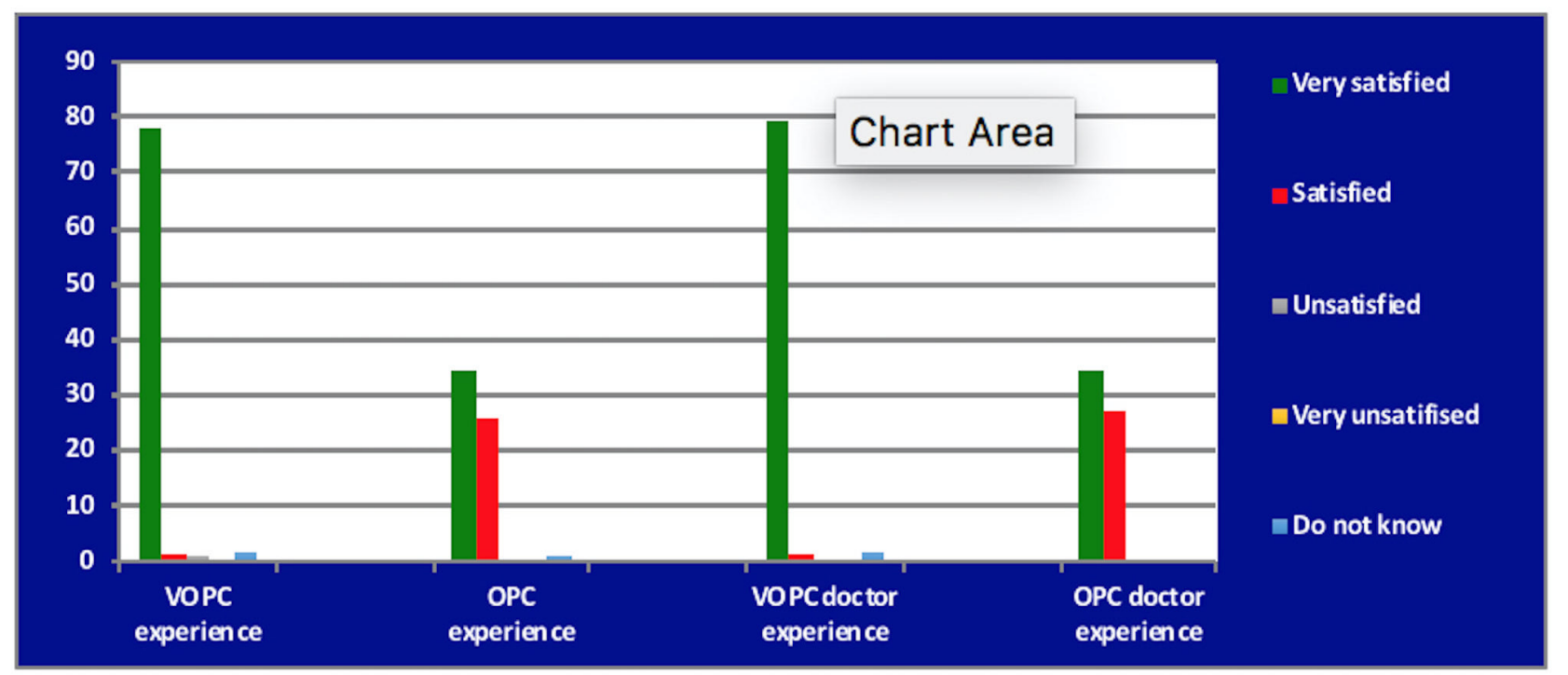

Figure 2 Reported satisfaction with clinic and doctor experience. OPC, outpatient clinic; VOPC, virtual outpatient clinic. 


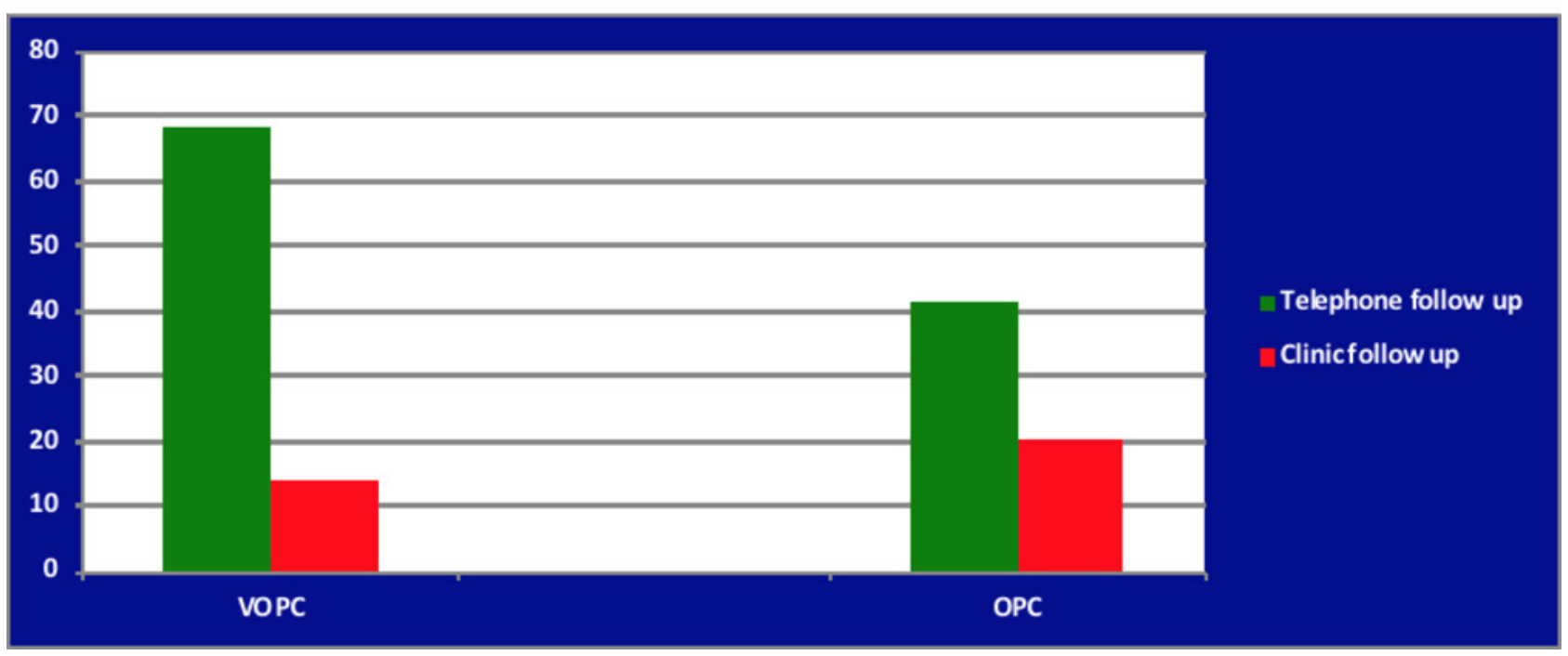

Figure 3 Patient preference for future follow-up. OPC, outpatient clinic; VOPC, virtual outpatient clinic.

\section{Table 3 Follow-up questionnaire}

\begin{tabular}{|c|c|c|c|c|}
\hline $\begin{array}{l}\text { Question } \\
\text { Number }\end{array}$ & Question & $\begin{array}{l}\text { OPC group } \\
(\mathrm{n}=61)\end{array}$ & $\begin{array}{l}\text { VOPC group } \\
(\mathrm{n}=81)\end{array}$ & $\begin{array}{l}\text { Sig } \chi^{2} \text { or } \\
\text { *Wilcoxon } \\
\text { Mann } \\
\text { Whitney test }\end{array}$ \\
\hline 1 & $\begin{array}{l}\text { Have you been back to your family doctor with the same or similar a problem since } \\
\text { your discharge? }\end{array}$ & 6 & 10 & 0.640 \\
\hline 2 & Have you any ongoing symptoms to report? & 6 & 10 & 0.640 \\
\hline 3 & Have you had any further surgery relating to your initial complaint? & 0 & 0 & \\
\hline 4 & Did you experience any wound infections after your discharge? & 0 & 0 & \\
\hline 5 & $\begin{array}{l}\text { Did you have to take off work (OPC cohort) or would you have to take time of work } \\
\text { (VOPC cohort) to attend the outpatients? }\end{array}$ & 27 & 48 & 0.087 \\
\hline 6 & $\begin{array}{l}\text { Did/would attending the outpatients lead to a disruption of your family life for } \\
\text { example, required a child minder? }\end{array}$ & 4 & 11 & 0.178 \\
\hline 7 & $\begin{array}{l}\text { How did/would you travel to the outpatients? (A) Own car, (B) Got a lift, (C) Paid for a } \\
\text { taxi, (D) Public transport }\end{array}$ & $\begin{array}{ll}\text { A. } & 42 \\
\text { B. } & 12 \\
\text { C. } & 2 \\
\text { D. } & 5\end{array}$ & $\begin{array}{ll}\text { A. } & 63 \\
\text { B. } & 11 \\
\text { C. } & 2 \\
\text { D. } & 6\end{array}$ & \\
\hline 8 & How long did/would it take to travel to the outpatient department (minutes)? & $24(5-60)$ & $20(5-120)$ & \\
\hline 9 & How long did it take for you to be seen? & $49(5-120)$ & N/A & \\
\hline 10 & $\begin{array}{l}\text { Were you satisfied with your outpatient (OPC or VOPC) experience? (A) Very } \\
\text { unsatisfied, (B) Unsatisfied, (C) Satisfied, (D) Very Satisfied, (E) Don't know }\end{array}$ & $\begin{array}{ll}\text { A. } & 0 \\
\text { B. } & 0 \\
\text { C. } & 26 \\
\text { D. } & 34 \\
\text { E. } & 1\end{array}$ & $\begin{array}{ll}\text { A. } & 0 \\
\text { B. } & 1 \\
\text { C. } & 1 \\
\text { D. } & 78 \\
\text { E. } & 2\end{array}$ & $<0.0001^{*}$ \\
\hline 11 & $\begin{array}{l}\text { Were you satisfied with your experience of the doctor who saw you/rang you? (A) Very } \\
\text { unsatisfied, (B) Unsatisfied, (C) Satisfied, (D) Very satisfied, (E) Don't know }\end{array}$ & $\begin{array}{ll}\text { A. } & 0 \\
\text { B. } & 0 \\
\text { C. } & 27 \\
\text { D. } & 34 \\
\text { E. } & 0\end{array}$ & $\begin{array}{ll}\text { A. } & 0 \\
\text { B. } & 0 \\
\text { C. } & 1 \\
\text { D. } & 79 \\
\text { E. } & 2\end{array}$ & $<0.0001$ \\
\hline 12 & $\begin{array}{l}\text { Would you prefer a (A) telephone follow-up appointment or (B) hospital appointment if } \\
\text { you had a similar problem in the future? }\end{array}$ & $\begin{array}{ll}\text { A. } & 41 \\
\text { B. } & 20\end{array}$ & $\begin{array}{ll}\text { A. } & 68 \\
\text { B. } & 14\end{array}$ & 0.029 \\
\hline
\end{tabular}

OPC, outpatient clinic; VOPC, virtual outpatient clinic. 
issues or symptoms in the VOPC were also afforded an opportunity to attend for a OPC assessment, examination and consultant review. Despite this, there was still a difference between cohorts. If required to attend the OPC, patients identified significant burdens to attending including absence from work, travel time to clinic and waiting time to be seen.

The time from referral to review of new patients has been identified as a KPI target by National bodies in many countries. ${ }^{45}$ In the UK, the NHS constitution pledges that no patient should wait more than 2 weeks to see a specialist for a suspected cancer diagnosis or 18 weeks from referral to commence non-urgent treatment ${ }^{5}$ while in Ireland, the KPI requires that $85 \%$ of patients be seen within 52 weeks, but these KPIs are regularly exceeded. ${ }^{17}$ The demands on OPCs are such that $9 \%$ of patients wait more than 2 months for a specialist appointment in the USA. ${ }^{18}$ These demands place a significant burden on hospitals and clinicians to ensure an efficient use of available clinical resources. Various strategies have been implemented to improve the efficiency of outpatient services. A systematic review by Stubbs et $\mathrm{al}^{19}$ has shown that interventions such as telephone or text reminders improve non-attendance rates. But reducing non-attendance rates, instead of improving access for new patients may potentially impair it due to increased workload. Clearly the best way to increase access to this limited resource is to reserve it for those who need it most. Although not examined in this study, based on a 2:1 return patient to new patient appointment policy, approximately 100 new patient appointment slots would have been created in the time period involved.

While running the VOPC in this study took a significant amount of time, in addition to existing duties, the virtual clinic was conducted during time periods when the surgical team members involved did not have emergency or elective commitments. The virtual clinic could be run by a trained nurse practitioner with support from a clinician. In the oncology setting there is ample evidence that nurse led telephone follow-up is an effective method of delivering care. ${ }^{20}{ }^{21}$ In the context of lung, breast and colorectal cancer, patients report a high level of satisfaction with nurse led services. ${ }^{22}$ Telephone follow-up has been examined in both adult and paediatric populations following anorectal surgery, cholecystectomy, hernia repair, tonsillectomy and following endoscopy ${ }^{16-9} 12$ and has been found to be a safe and acceptable alternative with satisfaction rates exceeding 90\%. ${ }^{12}$ In this digital age, other and better technologies can be employed to enhance contact between patient and hospital such as text messaging, ${ }^{23}$ interactive voice response systems ${ }^{24} 25$ or web-based assessment tools ${ }^{26}$ or smartphone applications. ${ }^{27} \mathrm{We}$ are now using the results of this study as the basis for a proposal to compare/ascertain the feasibility and safety of a text message follow-up and compare it to a telephone follow-up.
Our study has a number of strengths. First, to our knowledge, it is the only randomised controlled trial to compare telephone follow-up directly with routine clinic attendance for a variety of general surgical patients. Only one other RCT compared telephone review with face-to-face appointment among postoperative patients but this was of a dental surgery practice. Unlike previous studies, we also included a broader range of patients, including those admitted on an emergency or elective basis as well as those who did not undergo a surgical procedure. Second, we also completed a further follow-up with both groups to assess overall satisfaction and to document any further issues.

We acknowledge that the use of our follow-up questionnaire which was devised specifically to assess the outcomes of interest in this study and conducted 2 months after the initial review could be regarded as a limitation of the study. As such the questionnaire has not been previously validated, unlike the patient satisfaction questionnaires such as the 36 item Short Form Survey $(\mathrm{SF}-36)^{28}$ which has been validated. We felt that other available questionnaires were more useful in assessing overall satisfaction with many variables including other aspects of their care not relevant to the study outcomes. We also felt that these questionnaires were more suitable as a postal questionnaire follow-up rather than a phone follow-up. Any concern that a VOPC review at 2 months may lead to a delay in assessing potential complications is offset by the option of review at any time by the family doctor or the emergency department which was available to all patients regardless of the assigned intervention and by offering a next clinic review to all patients who identified or expressed any concerns during the VOPC review.

While this study compared a VOPC review to a traditional OPC review, it did not perform a cost benefit analysis of delivering such a service. The main objectives of this study were to determine if a VOPC was a safe and acceptability alternate to traditional clinic follow-up, as to our knowledge this has not been established previously by means of a RCT. It should be acknowledged, however, that there were no extra resources employed or costs involved to conduct this study as all work was carried out by staff as part of their normal work commitment. Future studies may include a health economic analysis of delivering a VOPC compared with standard OPC.

In conclusion, a routine follow-up visit for the majority of general surgical conditions may not just be unnecessary but results in delay in seeing new patients and may generate unnecessary further investigations. In this digital age a virtual follow-up should suffice, but the exact method, whether by telephone, text and so on and by whom remains to be determined. While clinical decision-makers must be involved a more efficient use of clinical personnel is mandatory for more effective clinical practice. This would result in a reduction in unnecessary appointments and should lead to greater efficiencies and 
timely access to outpatient services for newly referred patients. Future studies could evaluate the potential role of a nurse-led VOPC along with a health economic analysis of such a service.

Acknowledgements We would like to thank Professor Ronan Conroy of the Division of Population Health Sciences, Royal College of Surgeons in Ireland, Dublin, Ireland for his advice and comments in preparing the manuscript for submission.

Contributors $\mathrm{PH}$ drafted the proposal required for Ethical approval, was involved in data collection and analysis and drafted the main manuscript for submission. LMcC was involved in data collection, patient recruitment and data analysis. RT, EF and AF were involved in recruiting patients. CC performed statistical analysis of the data. RC provided advice to address some comments raised by the reviewers and this is acknowledged in the paper. MA was involved in drafting the manuscript. TW devised/proposed the project, supervised the staff involved and was involved in drafting the manuscript.

Funding The authors have not declared a specific grant for this research from any funding agency in the public, commercial or not-for-profit sectors.

Competing interests None declared.

Patient consent Not required.

Ethics approval Connolly Hospital, Blanchardstown, Dublin, Research and Ethics Committee.

Provenance and peer review Not commissioned; externally peer reviewed.

Data sharing statement No additional unpublished data.

\section{REFERENCES}

1 Eisenberg D, Hwa K, Wren SM. Telephone follow-up by a midlevel provider after laparoscopic inguinal hernia repair instead of face-to-face clinic visit. JSLS 2015;19:e2014.00205.

2 McVay MR, Kelley KR, Mathews DL, et al. Postoperative follow-up: is a phone call enough? J Pediatr Surg 2008;43:83-6.

3 Chen DW, Davis RW, Balentine CJ, et al. Utility of routine postoperative visit after appendectomy and cholecystectomy with evaluation of mobile technology access in an urban safety net population. J Surg Res. 2014;190:478-83.

4 Health Service Executive, 2016. National service plan 2017 [Internet]. https://www.hse.ie/eng/services/publications/ serviceplans/Service-Plan-2017/2017-National-Service-Plan.pdf (cited 6 Jul 2017).

5 National Health Service. The Handbook to the NHS Constitution. Department of Health, 2015.

6 Allgar VL, Neal RD. Delays in the diagnosis of six cancers: analysis of data from the National Survey of NHS Patients: Cancer. Br J Cancer 2005;92:1959-70.

7 Olsson JK, Schultz EM, Gould MK. Timeliness of care in patients with lung cancer: a systematic review. Thorax. 2009;64:749-56.

8 Gray RT, Sut MK, Badger SA, et al. Post-operative telephone review is cost-effective and acceptable to patients. Ulster Med J 2010;79:76-9.

9 Rosbe KW, Jones D, Jalisi S, et al. Efficacy of postoperative follow-up telephone calls for patients who underwent adenotonsillectomy. Arch Otolaryngol Head Neck Surg 2000;126:718-21.

10 Fallaize RC, Tinline-Purvis C, Dixon AR, et al. Telephone follow-up following office anorectal surgery. Ann R Coll Surg Engl 2008;90:464-6.
11 Fallis WM, Scurrah D. Outpatient laparoscopic cholecystectomy: home visit versus telephone follow-up. Can J Surg 2001;44:39-44.

12 Rosbe KW, Jones D, Jalisi S, et al. Efficacy of postoperative follow-up telephone calls for patients who underwent adenotonsillectomy. Arch Otolaryngol Head Neck Surg 2000;126:718.

13 Mandal K, Dodds SG, Hildreth A, et al. Comparative study of first-day postoperative cataract review methods. J Cataract Refract Surg 2004;30:1966-71.

14 Ryan EM, Rogers AC, Hanly AM, et al. A virtual outpatient department provides a satisfactory patient experience following endoscopy. Int J Colorectal Dis 2014;29:359-64.

15 Thompson-Coon J, Abdul-Rahman AK, Whear R, et al. Telephone consultations in place of face to face outpatient consultations for patients discharged from hospital following surgery: a systematic review. BMC Health Serv Res 2013;13:128.

16 Bailey J, Roland M, Roberts C. Is follow up by specialists routinely needed after elective surgery? A controlled trial. $J$ Epidemiol Community Health 1999;53:118-24.

17 National Treatment Purchase Fund. Outpatient Waiting List. http://www.ntpf.ie/home/outpatient.htm (cited 6 Aug 2017).

18 The Commonwealth Fund. International Profiles of Healthcare Systems. New York: The Commonwealth Fund, 2013.

19 Stubbs ND, Geraci SA, Stephenson PL, et al. Methods to reduce outpatient non-attendance. Am J Med Sci 2012;344:211-9.

20 Sardell S, Sharpe G, Ashley S, et al. Evaluation of a nurse-led telephone clinic in the follow-up of patients with malignant glioma. Clin Oncol 2000;12:36-41.

21 Booker J, Eardley A, Cowan R, et al. Telephone first postintervention follow-up for men who have had radical radiotherapy to the prostate: evaluation of a novel service delivery approach. Eur J Oncol Nurs 2004;8:325-33.

22 Beaver K, Williamson S, Chalmers K. Telephone follow-up after treatment for breast cancer: views and experiences of patients and specialist breast care nurses. J Clin Nurs 2010;19:2916-24.

23 Wolff M, Balamuth F, Sampayo E. Improving adolescent pelvic inflammatory disease follow-up from the emergency Department: randomized controlled trial with text messages. Ann Emerg Med 2016;67:602-9.

24 Forster AJ, Boyle L, Shojania KG, et al. Identifying patients with post-discharge care problems using an interactive voice response system. J Gen Intern Med 2009;24:520-5.

25 Johansson BA, Remvall S, Malgerud R, et al. Interactive voice response - an automated follow-up technique for adolescents discharged from acute psychiatric inpatient care: a randomised controlled trial. Springerplus 2013;2:146.

26 Marsh J, Hoch JS, Bryant D, et al. Economic evaluation of web-based compared with in-person follow-up after total joint arthroplasty. J Bone Joint Surg Am 2014;96:1910-6.

27 Lyu KX, Zhao J, Wang B, et al. Smartphone application wechat for clinical follow-up of discharged patients with head and neck tumors: a randomized controlled trial. Chin Med J 2016;129:2816.

28 Monica 1776 Main Street Santa, 90401-3208 C, 2017. 36item short form survey from the RAND medical outcomes study. Available from: from:https://www.rand.org/health/ surveys_tools/mos/36-item-short-form.html (accessed $10 \mathrm{Nov}$ 2017). 